\title{
Host-Guest Hydrogen Atom Transfer Induced by Electron Capture
}

\author{
Changtong Hao* and František Tureček \\ Department of Chemistry, University of Washington, Seattle, Washington, USA
}

1,n-Alkanediammonium cations in noncovalent complexes with two dibenzo-18-crown-6ether (DBCE) ligands undergo an unusual intramolecular tandem hydrogen atom and proton transfer to the crown ether ligand upon charge reduction by electron capture. Deuterium labeling established that both migrating hydrogens originated from the ammonium groups. The double hydrogen transfer was found to depend on the length of the alkane chain connecting the ammonium groups. Ab initio calculations provided structures for select alkanediammonium dibenzo-18-crown-6-ether complexes and dissociation products. This first observation of an intra-complex hydrogen transfer is explained by the unusual electronic properties of the complexes and the substantial hydrogen atom affinity of the aromatic rings in the crown ligand. (J Am Soc Mass Spectrom 2009, 20, 639-651) (C) 2009 Published by Elsevier Inc. on behalf of American Society for Mass Spectrometry

$\mathrm{I}$ nteractions of gas-phase ions with host molecules such as crown ethers [1-3], cucurbitol [4-8], calixarenes [9-12], cyclodextrins [13-23], and other macrocyclic ligands [24-27] have been studied extensively by various mass spectrometric methods. The previous studies have been focused on molecular recognition of the guest ion by the host molecule [28-30] and used both thermodynamic equilibrium [31] and kinetic methods [32, 33] to study dissociation and displacement reactions in the gas phase. An interesting situation occurs when the charged host-guest complex is reduced by electron attachment in the gas phase. For example, electron-transfer to doubly charged 18crown-6-ether-peptide complexes has been shown to trigger backbone dissociations in competition with loss of the crown ligand [34]. Another recent study reported on electron-induced dissociations of 18-crown-6-ether complexes with doubly protonated $\alpha, \omega$-diaminoalkanes [35]. Electron capture in those complexes resulted in the loss of an ammonium hydrogen atom followed by loss of the crown molecule. Computational analysis of the dissociation energetics showed that the host-guest interaction by hydrogen bonding in the ion was substantially weakened by oneelectron reduction. However, unexpected results were obtained for femtosecond collisional electron-transfer from $\mathrm{Na}$ and $\mathrm{Cs}$ atoms to 18-crown-6-ether-1,n-alkanediammonium complexes that, in addition to loss of the crown-ether ligand, also induced dissociations of $\mathrm{C}-\mathrm{C}$ bonds in the diaminoalkane backbone, while retaining the noncovalent crownammonium. These backbone dissociations were estimated to be substantially more endothermic than the loss of the crown

Address reprint requests to Dr. F. Tureček, Department of Chemistry, University of Washington, Seattle, WA, USA. E-mail: turecek@chem.washington.edu * Current address: Department of Chemistry, York University, Toronto, Ontario, Canada. ether ligand and their occurrence was attributed to the formation of high excited states by near-resonant electrontransfer from the alkali metal atom [35].

In this article, we report another interesting phenomenon observed for electron capture dissociation [36] of dibenzo-18-crown-6-ether-1,n-alkanediammonium complexes. These complexes undergo intramolecular hydrogen transfer from the guest ion to the host molecule upon partial reduction by electron capture. We also report density functional theory calculations of ion structures and dissociation energetics to interpret the experimental data.

\section{Experimental}

\section{Materials}

1,n-Diaminoalkanes ( $n=4-7)$ and dibenzo-18-crown-6-ether (DBCE) were purchased from Sigma Aldrich (Milwaukee, $\mathrm{WI}$ ) and used as received. 1,n-Diaminoalkane.DBCE complexes were prepared in situ by mixing the components in 1:1 or 1:2 molar ratios in methanol or aqueous methanol solutions. Gas-phase ion complexes are represented such that a doubly protonated $1, n$-diaminoalkane with $m$ number of dibenzo-18-crown-6-ethers $(m=1$ or 2$)$ is $n$-mDBCE ${ }^{2+}$. Species that have undergone deuterium labeling such that they contain $x$ number of $\mathrm{D}$ atoms will be reported as $\mathrm{D}_{\mathrm{x}}-\boldsymbol{n}$-mDBCE. The $\mathrm{D}_{6}-\boldsymbol{n}-1 \mathrm{DBCE}$ and $\mathrm{D}_{6}-\boldsymbol{n}-2 \mathrm{DBCE}(\boldsymbol{n}=\mathbf{6}$ and 7) complexes were prepared in $\mathrm{CH}_{3} \mathrm{OD}$ and electrosprayed from $\mathrm{D}_{2} \mathrm{O}: \mathrm{CH}_{3} \mathrm{OD}$ solvent mixtures.

\section{Methods}

Electron capture dissociation (ECD) and infrared multiphoton dissociation (IRMPD) spectra of $1, n$ diaminoalkane-DBCE complexes (were measured on an actively shielded 4.7-T Fourier transform ion-
(C) 2009 Published by Elsevier Inc. on behalf of American Society for Mass Spectrometry. $1044-0305 / 09 / \$ 32.00$

doi:10.1016/j.jasms.2008.12.001
Published online December 9, 2008 Received October 17, 2008 Revised December 1, 2008 Accepted December 1, 2008 
cyclotron resonance (FT-ICR) mass spectrometer (APEX-III; Bruker Daltonics, Billerica, MA) upgraded with a mass-selective quadrupole (Q) front-end. Positive ions were produced by direct infusion into an external Apollo electrospray ion source (Bruker Daltonics) at a flow rate of $1.5 \mu \mathrm{L} / \mathrm{min}$ with the assistance of $\mathrm{N}_{2}$ nebulizing gas $(8.0 \mathrm{psi})$. The ESI source was operated under the following conditions: cylinder, $0 \mathrm{~V}$; capillary, $-4490 \mathrm{~V}$; end plate, $-4080 \mathrm{~V}$; cap exit, $90 \mathrm{~V}$; skimmer 1, 20 $\mathrm{V}$; skimmer 2, $5.8 \mathrm{~V}$; offset, $3 \mathrm{~V}$; trap and extract, $7.4 \mathrm{~V}$ and $-6.7 \mathrm{~V}$ respectively; drying gas $\left(\mathrm{N}_{2}\right), 3 \mathrm{~L} / \mathrm{min}$; drying temperature, $150{ }^{\circ} \mathrm{C}$. The generated ions were accumulated in the first hexapole for $0.1 \mathrm{~s}$, transferred into the mass-selective quadrupole, and the mass-selected ions were accumulated for 1 to $3 \mathrm{~s}$ in the second hexapole. Ion optics further transferred ions into an Infinity ICR cell where they were trapped by gating the trapping potentials. All spectra were acquired using apexControl 2.0 (Bruker Daltonics) and data were processed with DataAnalysis 3.4 (Bruker Daltonics). ECD experiments were performed with an indirectly heated cathode (Heatwave, Crescent Valley, BC, Canada) operated at 1.7 A of heater current. During the ECD event, ions were selected by the external quadrupole mass filter then transferred into the ICR cell where they were irradiated by a pulse of electrons for a duration of 300 to $500 \mathrm{~ms}$. The electron energy was adjusted by electrostatic potentials on the lens and grid elements of the Bruker ECD source to optimize the ECD ion formation. The electron energies cannot be measured on the Bruker instrument and are estimated to be within 5 to $10 \mathrm{eV}$. IRMPD experiments were performed using a 25-W infrared $\mathrm{CO}_{2}$ laser (Synrad, model 48-2-2; Mukilteo, WA). During the IRMPD event, ions were selected by the external quadrupole mass filter then transferred into the ICR cell where they were irradiated by a pulse of $20 \%$ laser power for a duration of $200 \mathrm{~ms}$. The $\mathrm{m} / \mathrm{z}$ values are reported as rounded-off integer numbers.

\section{Calculations}

Standard ab initio calculations were performed using the Gaussian 03 suite of programs [37]. Geometries were optimized by density functional theory calculations using Becke's hybrid functional (B3LYP) [38] and the 6-31G(d) basis set. These initial geometries were reoptimized using B3LYP with the $6-31+G(d, p)$ and $6-31++G(d, p)$ basis sets for closed shell and open-shell species, respectively. Select optimized structures are shown in the pertinent schemes and figures. Complete optimized structures of all local minima and transition states can be obtained from the corresponding author (F.T.) upon request. Note that the DBCE ligand has a rather rigid structure, which is imposed by the orthocondensed benzene rings, and structure optimizations do not necessitate extensive searches of the conformational space. Spin unrestricted calculations were performed for all open-shell systems. Stationary points were characterized by harmonic frequency calculations as local minima (all real frequencies) and first-order saddle points (one imaginary frequency). The calculated frequencies were scaled with 0.963 [39] and used to obtain zero-point energy corrections, enthalpies, and entropies. The rigid-rotor-harmonic-oscillator (RRHO) model was used in thermochemical calculations except for low-frequency modes where the vibrational enthalpy terms that exceeded 0.5 RT were replaced by free internal rotation terms equal to $0.5 \mathrm{RT}$.

Improved energies were obtained by single-point calculations at several levels of theory. For model benzo-1,4-dioxane systems (18 atoms) we performed B3LYP and Møller-Plesset theory (second order, frozen core) calculations using the $6-311++\mathrm{G}(3 \mathrm{df}, 2 \mathrm{p})$ splitvalence triple- $\zeta$ basis set furnished with polarization and diffuse functions. In addition, coupled-cluster calculations [40] with single, double and disconnected triple excitations [CCSD(T)] [41] were performed with the $6-311 G(d, p)$ basis set and extrapolated to $\operatorname{CCSD}(\mathrm{T}) /$ $6-311++G(3 d f, 2 p)$ using the standard linear formula. This is analogous to the G2(MP2) level of theory [42]. With the large dibenzocrown complexes (120 atoms), $\mathrm{MP} 2$ and $\operatorname{CCSD}(\mathrm{T})$ calculations were beyond our computational capabilities and, therefore, we performed single point calculations only with B3LYP and the 6-311 $++\mathrm{G}(2 \mathrm{~d}, \mathrm{p})$ basis set.

Vertical excited-state energies were calculated with time-dependent density functional theory [43] using the B3LYP functional and the $6-311++G(2 d, p)$ basis set. Atomic spin and charge densities were calculated using the natural population analysis (NPA) method [44]. Excitedstate wave functions were constructed as linear combinations of virtual orbitals with expansion coefficients obtained from TD-B3LYP/6-311++G(2d,p) calculations.

\section{Results}

\section{IRMPD and ECD Spectra}

Electrospray ionization of 1,n-diaminoalkane-DBCE complexes produced mixtures of singly and doubly protonated complexes. The doubly charged ions were selected by mass and activated for dissociation by infrared photon absorption or electron capture. The ion dissociations are exemplified with the mass spectra of 6-1DBCE ${ }^{2+}$ and $6-2 \mathrm{DBCE}^{2+}$. IRMPD of $6-1 \mathrm{DBCE}^{2+}(\mathrm{m} / \mathrm{z}$ $239)$ resulted in two series of ions (Figure 1a). The main ion series consisted of protonated DBCE, $(\mathrm{DBCE}+\mathrm{H})^{+}$ at $m / z 361$, and its dissociation products at $m / z 317,299$, 225, 207, 181, 163, and 137. These were formed by combined losses of $\mathrm{C}_{2} \mathrm{H}_{4} \mathrm{O}(44 \mathrm{Da}), \mathrm{C}_{8} \mathrm{H}_{8} \mathrm{O}_{2}$ (136 Da), and water, as depicted in Scheme 1. The other series consisted of protonated 1,6-hexanediamine $\left(6^{+}, \mathrm{m} / \mathrm{z}\right.$ $117)$ and its dissociation products. These assignments are supported by accurate mass measurements that provided elemental compositions for the ions detected in the IRMPD mass spectrum and the neutrals eliminated in the dissociations. The same ion series for dissociations of $(\mathrm{DBCE}+\mathrm{H})^{+}$was obtained from IRMPD of $4-1 \mathrm{DBCE}^{2+}, 5-1 \mathrm{DBCE}^{2+}$, and $7-1 \mathrm{DBCE}^{2+}$ 
(a)
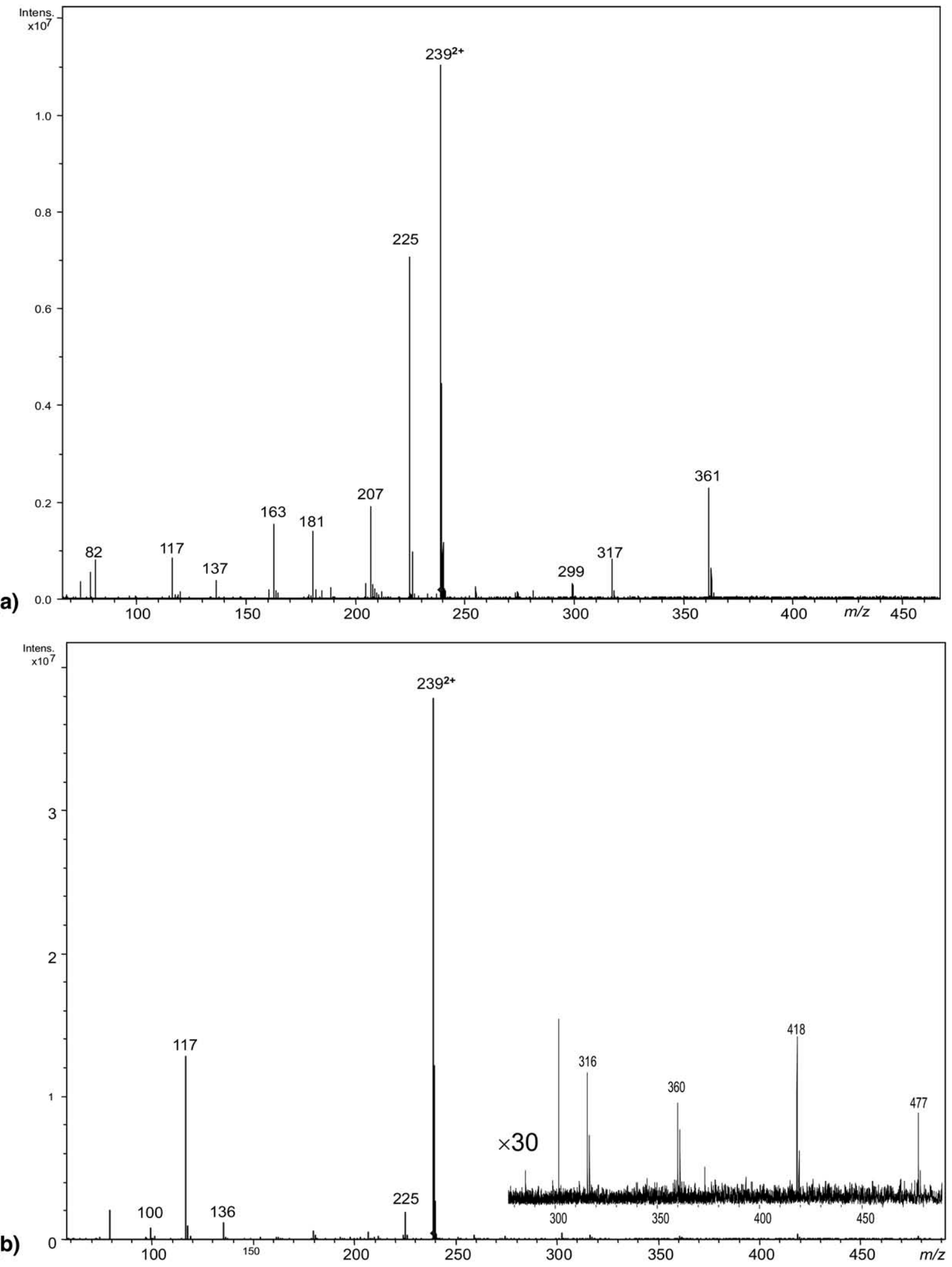

Figure 1. (a) IRMPD mass spectrum of mass selected 6-1DBCE ${ }^{2+}, m / z 239$; (b) ECD mass spectrum of mass-selected 6-1DBCE ${ }^{2+}$. Inset shows the expanded $m / z 280-480$ region.

although the fragment relative intensities somewhat differed. IRMPD of deuterium labeled $6-1 \mathrm{DBCE}^{2+}(\mathrm{a}$ mixture of $45 \% \mathrm{D}_{2}, 38 \% \mathrm{D}_{3}$, and $17 \% \mathrm{D}_{4}$ ) showed peaks of $(\mathrm{DBCE}+\mathrm{H})^{+}$and $(\mathrm{DBCE}+\mathrm{D})^{+}$of relative intensities that varied from 1:1 to 1:2 and indicated proton or deuteron transfer from the diammonium ion upon 


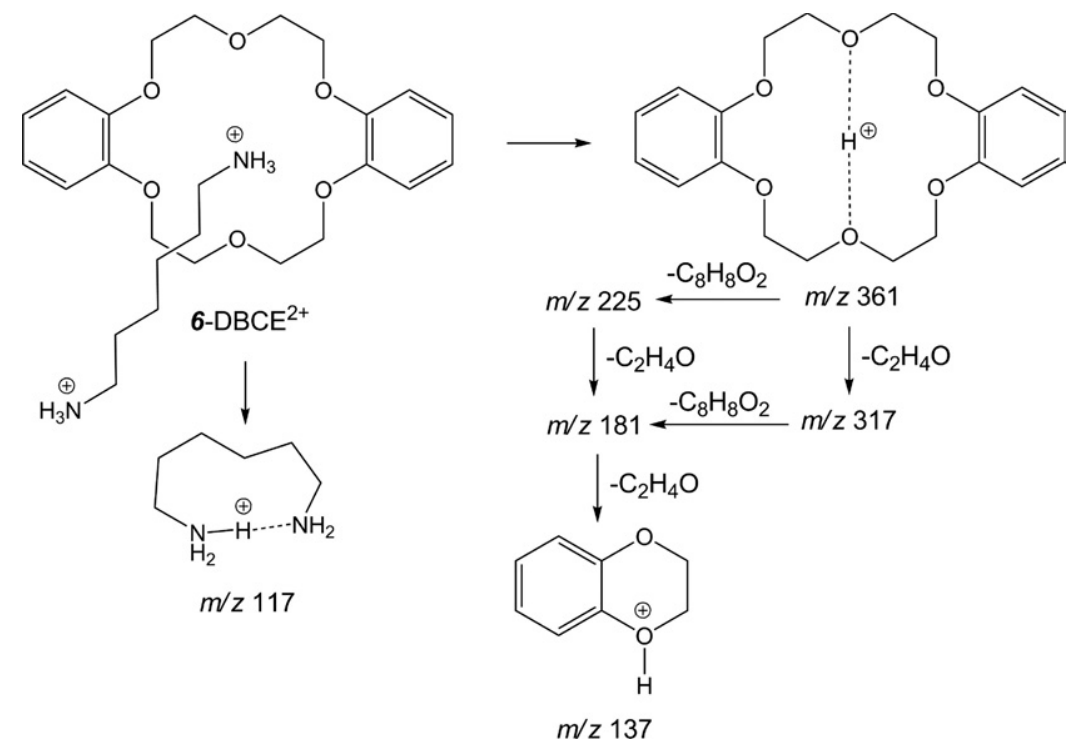

Scheme 1

dissociation. The $\mathrm{m} / \mathrm{z} 225,181$, and 137 fragment ions showed only $10 \%$ to $15 \%$ of their respective deuterated analogues, which was substantially lower than the D content of the precursor $6-1 \mathrm{DBCE}^{2+}$ ions. Presumably, the fragment ions underwent H/D exchange with residual water during their trapping in the cell that lowered the deuterium content faster than for the $(\mathrm{DBCE}+\mathrm{D})^{+}$ions. We note that all the reported deuterium contents are based on peak intensities that were corrected for the contributions of ${ }^{13} \mathrm{C}$ and ${ }^{15} \mathrm{~N}$ natural isotopes.

ECD of $6-1 \mathrm{DBCE}^{2+}$ gave $32 \%$ conversion of the precursor ion to singly charged products under our experimental conditions. ECD resulted in a complete dissociation of the charge-reduced $6-1 \mathrm{DBCE}^{+\cdot}$ intermediate (Figure $1 \mathrm{~b}$ ) and likewise for complexes of the other diaminoalkanes. The ECD spectrum showed a weak peak due to a loss of $\mathrm{H}$ at $\mathrm{m} / \mathrm{z} 477$ and a combined loss of $\mathrm{H}$ and 1,6-diaminohexane at $m / z$ 361. The latter fragment is presumably (DBCE + $\mathrm{H})^{+}$, as judged from its accurate mass and the presence of its dissociation products at $\mathrm{m} / \mathrm{z} 225$ and 181. The major product of ECD is at $\mathrm{m} / \mathrm{z} 117$ corresponding to protonated 1,6-diaminohexane $\left(6^{+}\right)$, which is formed by consecutive losses of $\mathrm{H}$ and $\mathrm{DBCE}$. These dissociations are analogous to those observed for alkanediammonium complexes of 18crown-6-ether as reported recently [35]. An interesting feature of the ECD spectra of the $n-1 \mathrm{DBCE}^{2+}$ complexes is the presence of weak odd-electron ions, e.g., at $m / z 180$ and 136. We presume that these were formed by electron impact ionization of neutral $\mathrm{C}_{10} \mathrm{H}_{12} \mathrm{O}_{3}$ and $\mathrm{C}_{8} \mathrm{H}_{8} \mathrm{O}_{2}$ fragments from $\mathrm{ECD}$ at the long irradiation times of our measurements. Note that benzo-1,4-dioxane, which is the presumed structure of the $136 \mathrm{Da}$ neutral, has a low ionization energy of $7.85 \mathrm{eV}$ and a somewhat lower value can be expected for the homologous $\mathrm{C}_{10} \mathrm{H}_{12} \mathrm{O}_{3}$ molecule. For reference, the ionization energy of DBCE was calculated to be $6.99 \mathrm{eV}$ (see below). Thus, these neutral fragments can be ionized by the electron beam entering the ICR cell.
IRMPD of $6-2 \mathrm{DBCE}^{2+}(\mathrm{m} / z$ 419, Figure 2a) formed fragments by loss of $(\mathrm{DBCE}+\mathrm{H})^{+}$at $\mathrm{m} / \mathrm{z} 477$, and a complementary ion series starting with $(\mathrm{DBCE}+\mathrm{H})^{+}$at $\mathrm{m} / \mathrm{z} 361$, and continuing with its fragments at $\mathrm{m} / \mathrm{z} 225$, $207,181,163$, and 137. A major peak of $\boldsymbol{6}^{+}$appeared at $\mathrm{m} / \mathrm{z}$ 117. IRMPD mass spectra of $4-2 \mathrm{DBCE}^{2+}$ through $7-2 \mathrm{DBCE}^{2+}$ were quite analogous to that of $6-2 \mathrm{DBCE}^{2+}$.

ECD of $6-2 \mathrm{DBCE}^{2+}(\mathrm{m} / \mathrm{z} 419$, Figure $2 \mathrm{~b})$ provided charge-reduced ions at $50 \%$ conversion of the precursor ion. We note that analogous 18-crown-6-etheralkanediammonium complexes also showed greater ECD conversions for doubly-coordinated ions compared with those for singly coordinated ones [35]. More importantly, the ECD spectrum of $6-2 D_{B C E}{ }^{2+}$ revealed some novel dissociations that are analyzed in some detail. The ECD spectrum showed neither a chargereduced ion $(\mathrm{m} / \mathrm{z} 838)$ nor a fragment by loss of an $\mathrm{H}$ atom. A major fragment ion was observed at $m / z 477$, which arose by a combined loss of $\mathrm{H}$ and DBCE. Further dissociation by loss of a second molecule of DBCE formed the $\boldsymbol{\sigma}^{+}$ion at $\mathrm{m} / \mathrm{z} 117$. However, the spectrum showed an unexpected odd-electron fragment at $m / z 362$, which had an elemental composition of $\mathrm{C}_{20} \mathrm{H}_{26} \mathrm{O}_{6}$ (measured 362.1722, theoretical 362.1729). This corresponded to $\mathrm{DBCE}$, which received a proton and a hydrogen atom as a result of charge-reduction and dissociation. This fragment is denoted as Z. ECD of $6-2 \mathrm{DBCE}^{2+}$ in which the ammonium protons were exchanged for deuterium, $\left(62 \% \mathrm{D}_{6}, 36 \% \mathrm{D}_{5}\right.$, and $\left.2 \% \mathrm{D}_{4}\right)$ showed $77 \%$ of $\mathrm{D}_{2}-\mathrm{Z}$ at $\mathrm{m} / \mathrm{z} 364$ and $23 \% \mathrm{D}_{1}-\mathbf{Z}$ at $m / z 363$, consistent with a transfer of an ammonium proton and an ammonium hydrogen atom to DBCE. Note that a purely statistical transfer of two ammonium hydrogens (no isotope effects) would form $86 \%$ Z- $\mathrm{D}_{2}$ and $13 \% \mathbf{Z}-\mathrm{D}_{1}$. The experimental distribution may indicate an isotope effect favoring transfer of $\mathrm{H}$ during the dissociation, or an H/D exchange with the background water vapor during the ion storage in the ICR cell. Nevertheless, the ECD spectrum indicates a major transfer of two ammonium hydrogens to the $\mathbf{Z}$ fragment. 
(a)
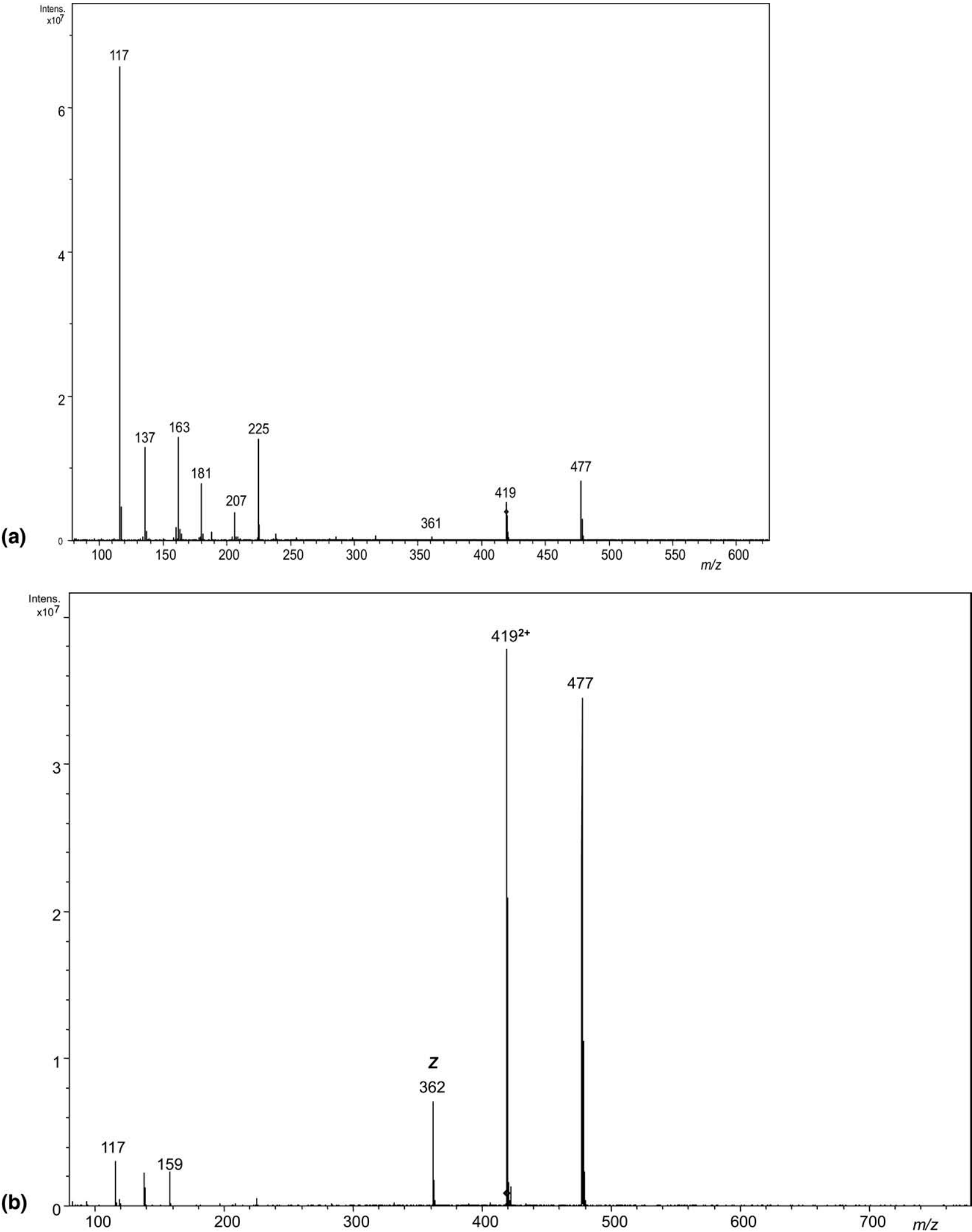

Figure 2. (a) IRMPD mass spectrum of mass selected 6-2DBCE ${ }^{2+}, m / z 239 ;$ (b) ECD mass spectrum of mass-selected $6-2 \mathrm{DBCE}^{2+}$.

The relative intensity of the $\mathbf{Z}$ fragment was found to depend on the alkanediamine chain length. For $n=7$ and 6 , the $\mathbf{Z}$ fragment amounted to $15 \%$ to $17 \%$ of the sum of charge-reduced ion intensities. For $n=5$ and 4 , the $\mathbf{Z}$ fragment relative intensity dropped to $8 \%$ and $2 \%$, respectively. The combined formation of $D_{2}-\mathbf{Z}$ and $D_{1}-\mathbf{Z}$ 
from $\mathrm{D}_{6}-6-2 \mathrm{DBCE}^{2+}$ of the above-described isotope distribution was $17 \%$, indicating no major isotope effects in the $\mathbf{Z}$ fragment formation.

\section{Ion and Radical Structures and Energetics}

To gain further insight into the unexpected formation of the $\mathbf{Z}$ fragment, we carried out electron structure theory calculations of several relevant species. The questions we attempted to address by calculations were (1) precursor ion structure, (2) recombination energy, (3) chargereduced ion structure, (4) proton and hydrogen atom affinity of the dibenzocrown ligand, (5) dissociation energies of the ECD intermediates, and (6) their electronic properties. These topics will be described and discussed below.

Because of the substantial molecular size of the present complexes, e.g., $\mathrm{C}_{47} \mathrm{H}_{68} \mathrm{~N}_{2} \mathrm{O}_{12}$ or 129 atoms for $7-2 \mathrm{DBCE}^{2+}$, the calculations focused on the smallest $4-2 \mathrm{DBCE}^{2+}$ ion and its dissociation products and used density functional theory only. In addition, we used higher level combined B3-MP2 [45] and $\operatorname{CCSD}(\mathrm{T})$ [41] calculations to model hydrogen transfer reactions with benzo-1,4-dioxane as a DBCE fragment of presumably analogous electronic properties. The optimized structure of the 4-2DBCE ${ }^{2+}$ ion is shown in Scheme 2. Each ammonium group is bound by two hydrogen bonds to the DBCE phenol oxygens and by another hydrogen bond to the ether chain middle oxygen. The $\mathrm{H}-\mathrm{O}$ hydrogen bonds have standard lengths of 1.83 to $1.9 \AA$.
The DBCE ligands in the gas-phase 4-2DBCE ${ }^{2+}$ complex have slightly distorted bowl conformations which are similar to that in a crystalline ammonium complex as determined by $X$-ray crystallography $[46,47]$. Complex 4-2DBCE ${ }^{2+}$ shows substantial stability to dissociation by loss of a neutral DBCE ligand forming $4-\mathrm{DBCE}^{2+}$, which requires $220 \mathrm{~kJ} \mathrm{~mol}^{-1}$ at the thermochemical threshold (Table 1). In contrast, proton transfer to DBCE in $4-2 \mathrm{DBCE}^{2+}$ followed by dissociation to $4-1 \mathrm{DBCE}^{+}$ and $(\mathrm{DBCE}+\mathrm{H})^{+}$is $13 \mathrm{~kJ} \mathrm{~mol}^{-1}$ exothermic (Table 1), indicating that the $4-2 \mathrm{DBCE}^{2+}$ complex owes its existence to an energy barrier to this exothermic dissociation. The formation of $4-1 \mathrm{DBCE}^{+}$and $(\mathrm{DBCE}+\mathrm{H})^{+}$is expected to represent the major dissociation of the doubly charged complex, consistent with the IRMPD spectrum.

Loss of the second DBCE molecule from 4-1DBCE ${ }^{2+}$ to form $4^{2+}$ requires $279 \mathrm{~kJ} \mathrm{~mol}^{-1}$ (Table 1 ). In contrast, proton transfer and dissociation to $4^{+}$and (DBCE + $\mathrm{H})^{+}$is $71 \mathrm{~kJ} \mathrm{~mol}^{-1}$ exothermic. Note that this dissociation is made exothermic by the substantial stabilization of $4^{+}$by intramolecular hydrogen bonding between the $\mathrm{NH}_{3}{ }^{+}$and $\mathrm{NH}_{2}$ groups, which is estimated at $85 \mathrm{~kJ}$ $\mathrm{mol}^{-1}$ and which is absent in 4-1DBCE ${ }^{2+}$. Hence, dissociation to $4^{+}$and $(\mathrm{DBCE}+\mathrm{H})^{+}$is likely to require an activation energy that kinetically stabilizes the complex to be observable in the gas-phase.

Loss of neutral DBCE from $4-1 \mathrm{DBCE}^{+}$requires $123 \mathrm{~kJ}$ $\mathrm{mol}^{-1}$ at the thermochemical threshold. The complementary formation of $(\mathrm{DBCE}+\mathrm{H})^{+}$by loss of neutral 4 is

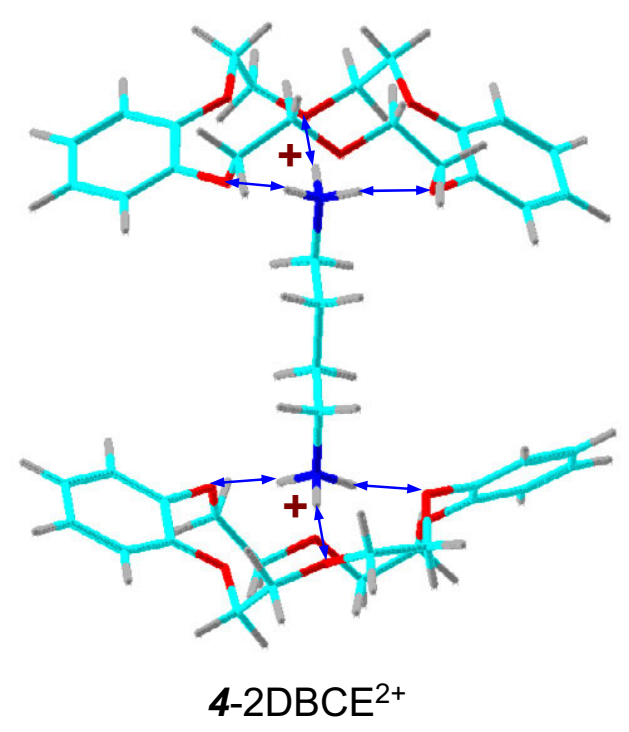

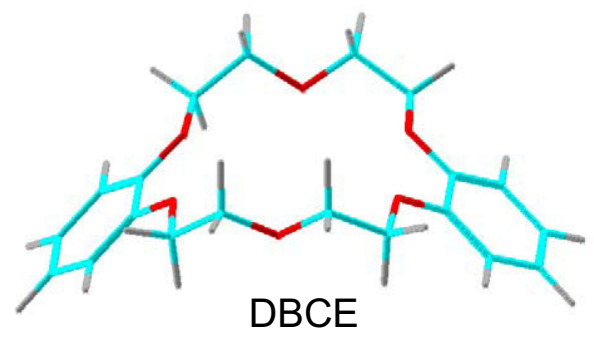

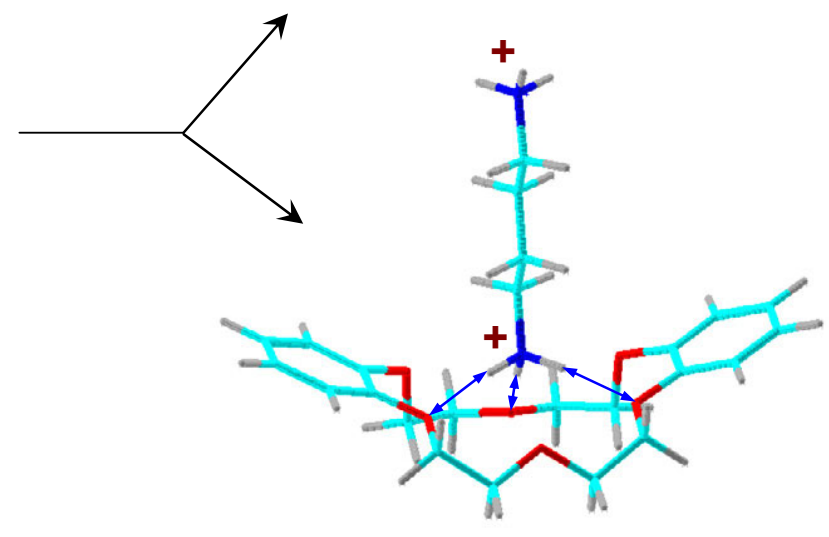

4-DBCE ${ }^{2+}$ 
Table 1. Ion relative and dissociation energies

\begin{tabular}{|c|c|c|c|}
\hline \multirow[b]{2}{*}{ Species/reaction } & \multicolumn{3}{|c|}{ Relative energy ${ }^{a, b}$} \\
\hline & $\begin{array}{c}\text { B3LYP } \\
6-31+G(d, p)\end{array}$ & $\begin{array}{c}\text { B3LYP } \\
6-311++G(2 d, p)\end{array}$ & $\begin{array}{c}\text { B3-PMP2 }^{c} \\
6-311++G(2 d, p)\end{array}$ \\
\hline 4-2DBCE ${ }^{2+} \rightarrow$ 4-1DBCE ${ }^{2+}+$ DBCE & 230 & 220 & - \\
\hline 4-2DBCE ${ }^{2+} \rightarrow$ 4-1DBCE ${ }^{+}+(\mathrm{DBCE}+\mathrm{H})^{+}$ & -8 & -13 & - \\
\hline 4-1DBCE ${ }^{2+} \rightarrow 4^{2+}+\mathrm{DBCE}$ & 291 & 279 & - \\
\hline 4-1DBCE ${ }^{2+} \rightarrow \mathbf{4}^{+}+(\mathrm{DBCE}+\mathrm{H})^{+}$ & -71 & -71 & - \\
\hline 4-1DBCE ${ }^{+} \rightarrow \mathbf{4}^{+}+$DBCE & 129 & 123 & - \\
\hline 4-1DBCE ${ }^{+} \rightarrow \mathbf{4}+(\mathrm{DBCE}+\mathrm{H})^{+}$ & 206 & 203 & - \\
\hline $\mathbf{4}^{+} \rightarrow \mathbf{4}+\mathrm{H}^{+}$ & 1008 & 1000 & $998(1005)^{d}$ \\
\hline $\mathbf{8} \mathbf{a}^{+} \rightarrow \mathrm{DBCE}+\mathrm{H}^{+}$ & 930 & 919 & $934(939)^{d}$ \\
\hline $\mathbf{8 b}^{+} \rightarrow \mathrm{DBCE}+\mathrm{H}^{+}$ & 930 & 920 & $933(939)^{d}$ \\
\hline $\mathbf{8 c}^{+} \rightarrow \mathrm{DBCE}+\mathrm{H}^{+}$ & 924 & 914 & $928(934)^{d}$ \\
\hline $\mathbf{8 d}^{+} \rightarrow \mathrm{DBCE}+\mathrm{H}^{+}$ & 887 & 880 & - \\
\hline $\mathbf{9}^{+\bullet} \rightarrow(\mathrm{DBCE}+\mathrm{H})^{\bullet}+\mathrm{H}^{+}$ & 932 & 921 & $936(941)^{d}$ \\
\hline $\mathbf{9}^{+\bullet} \rightarrow(\mathrm{DBCE}+\mathrm{H})^{+}+\mathrm{H}^{\bullet}$ & 101 & 97 & 75 \\
\hline$(\mathrm{DBCE}+\mathrm{H})^{\bullet} \rightarrow \mathrm{DBCE}+\mathrm{H}^{\bullet}$ & 100 & 95 & 73 \\
\hline $12^{+} \rightarrow \mathbf{8} \mathbf{a}^{+}+\mathrm{CH}_{3} \mathrm{NH}_{2}$ & 198 & 193 & 203 \\
\hline $12^{+} \rightarrow \mathrm{DBCE}+\mathrm{CH}_{3} \mathrm{NH}_{3}^{+}$ & 232 & 220 & 245 \\
\hline $12^{+} \rightarrow 13 b+\mathrm{H}^{+}$ & 1116 & 1104 & $1115(1122)^{d}$ \\
\hline $13 \mathbf{a} \rightarrow \mathrm{DBCE}+\mathrm{CH}_{3} \mathrm{NH}_{2}$ & 6 & 3 & 17 \\
\hline $\mathbf{1 3 b} \rightarrow \mathrm{DBCE}+\mathrm{CH}_{3} \mathrm{NH}_{2}$ & 11 & 8 & 21 \\
\hline
\end{tabular}

an units of $\mathrm{kJ} \mathrm{mol}^{-1}$

b Including zero-point energies and referring to $0 \mathrm{~K}$ unless stated otherwise.

${ }^{c} E[B 3-P M P 2]=0.5\{E[B 3 L Y P]+E[P M P 2]\}$ (reference [45]).

dProton affinities at $298 \mathrm{~K}$.

more endothermic (203 $\mathrm{kJ} \mathrm{mol}^{-1}$ ) and the difference reflects the lower proton affinity of DBCE compared to 4 . The calculated proton affinities are collated in Table 1 . The lower binding energy in 4-1DBCE ${ }^{+}$determines its stability when formed as an intermediate by ECD of $4-2 \mathrm{DBCE}^{2+}$. Similar binding energies can be expected for $5-1 \mathrm{DBCE}^{+}$ through 7-1DBCE ${ }^{+}$.

Electron capture in 4-2DBCE ${ }^{2+}$ forms a cation-radical intermediate 4-2 $\mathrm{DBCE}^{+\cdot}$. Unfortunately, both HartreeFock and DFT calculations of $4-2 \mathrm{DBCE}^{+\cdot}$ repeatedly failed to reach convergence, and therefore we were unable to obtain an optimized structure. Hence, the question of existence of $4-2 \mathrm{DBCE}^{+\cdot}$ as a local energy minimum remains open. A single point calculation gave the vertical recombination energy for $4-2 \mathrm{DBCE}^{2+}+e \rightarrow$ $4-2 \mathrm{DBCE}^{+\cdot}$ as $3.69 \mathrm{eV}$, a very low value for a dication.

The ability of DBCE to bind a hydrogen atom and a proton was established from calculations of hydrogen atom and proton affinities. Regarding the latter, the $C_{2 v}$ symmetry of DBCE allows for six prototrophic isomers for $(\mathrm{DBCE}+\mathrm{H})^{+}$in which the proton is bound to one oxygen atom and internally solvated by another. Aromatic ring-protonated structures would not allow for intramolecular hydrogen bonding and therefore were not considered. We found ion structures $\mathbf{8 a ^ { + }}$ and $\mathbf{8 b ^ { + }}$ as being practically isoenergetic, while $8 \mathrm{c}^{+}$and $8 \mathrm{~d}^{+}$were less stable (Figure 3 ). Ion $\mathbf{8 a ^ { + }}$ has the proton attached to a phenol oxygen and solvated by the proximate phenol oxygen from the other ring at a $1.332 \AA \mathrm{H}-\mathrm{O}$ distance. Structure $8 \mathrm{~b}^{+}$has the proton attached to the middle ether oxygen and solvated by the middle ether oxygen across the ring at a $1.419 \AA \mathrm{H}-\mathrm{O}$ distance. The more constrained ring structure in $\mathbf{8 b ^ { + }}$ is reflected by its lower entropy, so that $\mathbf{8 b ^ { + }}$ is disfavored against $\mathbf{8 a ^ { + }}$ by $\Delta G_{\mathrm{g}, 298}\left(\mathbf{8 a}^{+} \rightarrow \mathbf{8 \mathbf { b } ^ { + }}\right)=5 \mathrm{~kJ} \mathrm{~mol}^{-1}$. The calculated proton affinity of $\mathbf{8 \mathbf { a } ^ { + }}$ and $\mathbf{8 \mathbf { b } ^ { + }}\left(\mathrm{PA}=939 \mathrm{~kJ} \mathrm{~mol}^{-1}\right)$ is lower than that calculated for 1,4-butanediamine (1005 kJ $\left.\mathrm{mol}^{-1}\right)$. This explains the proton partitioning between the fragments from dissociation of 4 - $\mathrm{DBCE}^{+}$where $4^{+}$ is preferred. Note that whereas an experimental PA of DBCE is not available, that for 1,4-butanediamine (1006 $\mathrm{kJ} \mathrm{mol}^{-1}$ ) [48] is in a good agreement with the value from our B3-MP2/6-311+ $+\mathrm{G}(2 \mathrm{~d}, \mathrm{p})$ calculations.

The hydrogen atom affinity of protonated DBCE was calculated for isomer $\mathbf{8 a}^{+}$and $\mathrm{H}$-atom addition to the ortho-position of the solvating phenol oxygen (Scheme 3 ). The cation-radical structure $\left(\mathbf{9}^{+\cdot}\right)$ shows a planar dihydrobenzene ring, which accommodates the entire unpaired electron density. The spin density is delocalized among the carbon atoms, which are ortho and para to the H-atom addition site. Interestingly, there is no spin spillover to the crown ether or the other aromatic ring. The hydrogen atom affinity for $\mathbf{9}^{+\cdot} \rightarrow \mathbf{8 \mathbf { a } ^ { + }}+\mathrm{H}^{-}$was calculated as $75 \mathrm{~kJ}$ $\mathrm{mol}^{-1}$, indicating a moderately exothermic $\mathrm{H}$-atom addition. Hence structure $\mathbf{9}^{+\cdot}$ can be a plausible representation of ion $\mathbf{Z}$.

However, the electronic system in $\mathbf{9}^{+\cdot}$ is still rather large and allows for many isomers differing in various combinations of proton and $\mathrm{H}$-atom positions. To investigate the relative thermodynamic and kinetic stabilities of various $\mathrm{H}$-atom adducts, we addressed the activation energy for the $\mathrm{H}$-atom addition to the simpler benzo-1,4-dioxane system 10 which, owing to its symmetry, allows for only three isomers (11a-11c, 

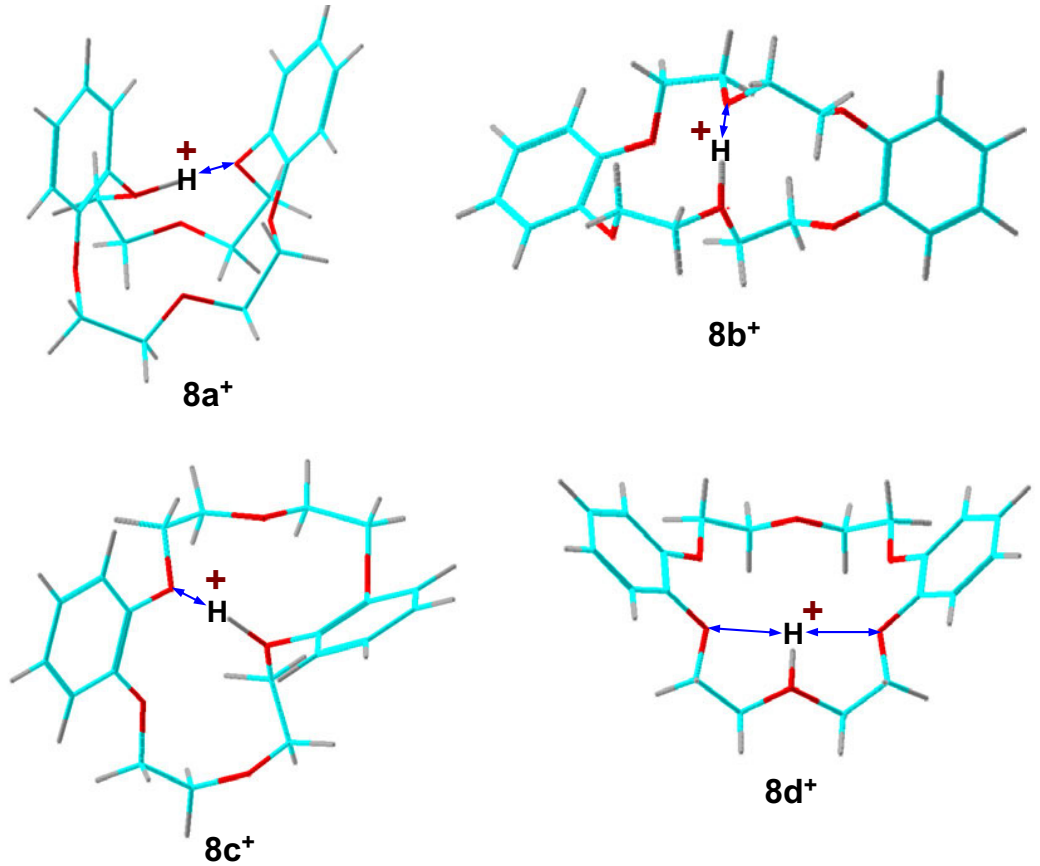

Figure 3. B3LYP-6-31+G(d,p) optimized structures of $(\mathrm{DBCE}+\mathrm{H})^{+}$ions $\mathbf{8} \mathbf{a}^{+}-\mathbf{8} \mathbf{d}^{+}$. Atoms are color-coded as follows: turquoise: $\mathrm{C}$; red: $\mathrm{O}$; gray: $\mathrm{H}$. Blue double-headed arrows indicate hydrogen bonds.

Scheme 4). The calculated energies are summarized in Table 2. The H-atom affinities were found to range between 60 and $87 \mathrm{~kJ} \mathrm{~mol}^{-1}$ at various levels of theory (Table 2), which were similar to that calculated for $\mathbf{8 a}$. The ortho-positions (C-3, C-6) gave the most stable adduct (11b). All $\mathrm{H}$-atom additions required activation energies which ranged between 26 and $39 \mathrm{~kJ}$ $\mathrm{mol}^{-1}$, again depending on the level of theory. The combination of the $\mathrm{H}$-atom affinity and activation energy increased the overall stability of the adducts to $101-120 \mathrm{~kJ} \mathrm{~mol}{ }^{-1}$, whereby the ortho adduct was the most stable isomer.

\section{Electronic Properties of DBCE-Ammonium Complexes and Dissociation Mechanisms}

As mentioned above, electronic structure theory calculations of $4-2 \mathrm{DBCE}^{+\cdot}$ and other intermediates were difficult and did not furnish specific results because of convergence failures. Therefore, we resorted to model these systems with a simpler one consisting of DBCE and methylammonium ion $\left(\mathbf{1 2}^{+}\right)$, radical (12), and neutral methylamine (13a,b) (Scheme 5). We used a similar model in the previous work on 18-crown-6-ether complexes where it provided a useful reference [35]. Of course, model 12 neglects the effect of a residual charge which is present in $4-2 \mathrm{DBCE}^{+\cdot}$ following charge reduction. Nevertheless, 12 turned out to provide a useful insight, which is now briefly described and discussed. Electron attachment to $\mathbf{1 2}^{+}$is associated with a vertical recombination energy of $2.05 \mathrm{eV}$. This is to be compared with the $\mathrm{RE}_{\mathrm{v}}$ for a 18-crown-6-ether $\mathrm{CH}_{3} \mathrm{NH}_{3}{ }^{+}$complex $(1.74 \mathrm{eV})$ [49]. These $\mathrm{RE}_{\mathrm{v}}$ values indicate that the electron binding energies in crown-solvated ammonium ions are extremely low, much lower than the recombination energies of free, nonsolvated ammonium groups, which are

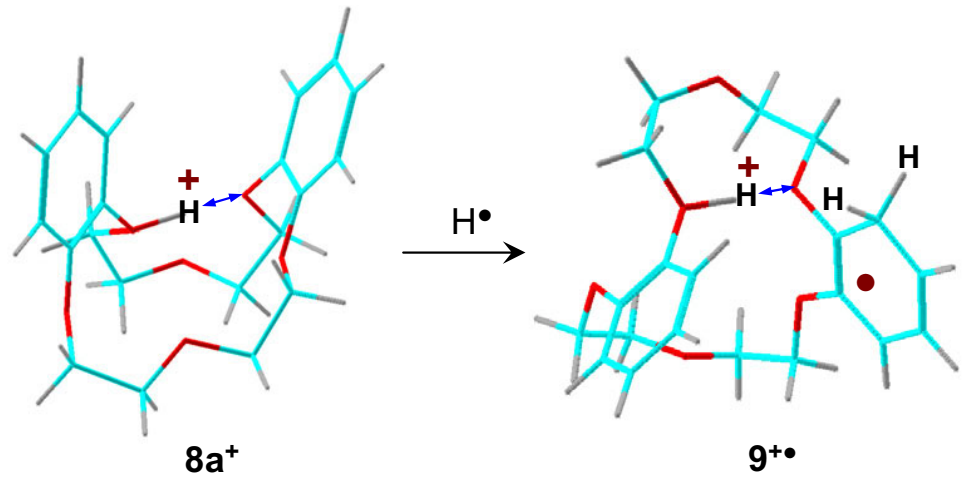

Scheme 3 
<smiles>c1ccc2c(c1)OCCO2</smiles>
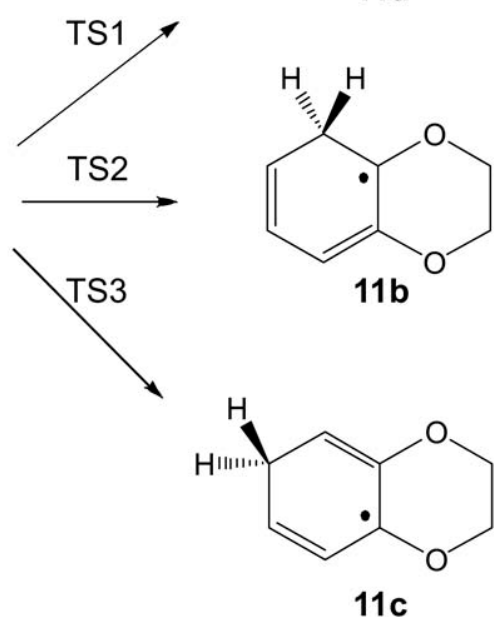

Scheme 4

typically in the $4.0-4.2 \mathrm{eV}$ range [50]. Thus, electron attachment to $4-1 \mathrm{DBCE}^{2+}$ and its higher homologues is expected to reduce the nonsolvated ammonium group while retaining the solvated one as a cation. This is consistent with the dissociations upon electron capture that show loss of an ammonium hydrogen atom and the crown-ether ligand. However, when both ammonium groups are solvated, as in $4-2 \mathrm{DBCE}^{2+}$ and its higher homologues, the incoming electron must interact with the solvated ammonium groups, and this interaction triggers unusual behavior accompanied by hydrogen migrations.

The salient features of electron attachment to crown ether solvated ammonium, as in the model DBCE. $\mathrm{CH}_{3} \mathrm{NH}_{3}{ }^{+}$ complex, are revealed by the analysis of the ground and excited electronic states in $\mathbf{1 2}$ (Figure 4). This showed that the ground doublet $(X)$ and the first excited $(A)$ state were nearly degenerate. The molecular orbital representing the $X$ state (SOMO, 106 $\alpha$ ) was a $\pi^{*}$-orbital delocalized over both aromatic rings of the DBCE ligand. The $A$ state of a nearly identical energy was represented by a Rydberg-like 3s orbital surrounding the methyl group. Among the higher excited states, $C$ was represented by another aromatic $\pi^{*}$-orbital, $\boldsymbol{B}$ and $\boldsymbol{E}$ were Rydbergs, and $\boldsymbol{D}$ was a combination of a $3 \mathrm{~s}$ Rydberg and an aromatic $\pi^{*}$-orbital. The interesting feature of all these states is that the neutralizing electron is insulated from the ammonium group which retains a positive charge after reduction while carrying negligible unpaired electron density. The novel feature of the DBCE complexes is the formation of states that contain the electron in the aromatic $\pi$-system in the form of a radical anion. According to the calculated electron distributions, such states can be viewed as zwitterionic. Note that the aromatic systems in neutral alkoxybenzenes do not have bound states for an extra electron. The stability of $\mathbf{1 2}$ is due to Coulomb effects of the proximate ammonium charge [51, 52]. However, the aromatic anion in the $X, C, D$, and presumably also in higher electronic states of $\mathbf{1 2}$ is expected to be substantially basic to induce exothermic migration of an ammonium proton [51]. This would quench the zwitterionic state and form a complex of neutral amine with a $(\mathrm{DBCE}+\mathrm{H})$ radical. The binding energy of a neutral amine to $(\mathrm{DBCE}+\mathrm{H})$ is unknown but can be approximated by that in DBCE. $\mathrm{CH}_{3} \mathrm{NH}_{2}$ neutral complexes $\mathbf{1 3 a}, \mathbf{b}$. Table 1 shows that the binding is very weak and the components are expected to dissociate rapidly at thermal energies.

Our experiments did not allow us to distinguish the loss of the $(\mathrm{DBCE}+\mathrm{H})$ radical from charge-reduced 4-2DBCE ${ }^{+\cdot}$ and its homologues from a sequential loss of an ammonium hydrogen atom and a DBCE ligand, as both dissociations result in an abundant formation of 4-1DBCE ${ }^{+}$product ions that dominate the ECD spectra. The interesting aspect of the ECD spectra is that the loss of $\mathrm{DBCE}$ and $\mathrm{H}^{\circ}$ competes with a proton transfer to $(\mathrm{DBCE}+\mathrm{H})$. The proton most likely originates from the

Table 2. Hydrogen atom affinities and activation energies

\begin{tabular}{|c|c|c|c|}
\hline \multirow[b]{2}{*}{ Species/reaction } & \multicolumn{3}{|c|}{ Relative energy ${ }^{a}$} \\
\hline & $\begin{array}{c}\text { B3LYP } \\
6-31+G(d, p)\end{array}$ & $\begin{array}{c}\text { B3-PMP2 }^{\text {b }} \\
6-311++G(3 d f, 2 p)\end{array}$ & $\begin{array}{c}\operatorname{CCSD}(T)^{c} \\
6-311++G(3 d f, 2 p)\end{array}$ \\
\hline $11 a \rightarrow 10+H$ & 85 & 60 & 67 \\
\hline $10+\mathrm{H} \rightarrow \mathrm{TS} 1$ & 16 & 33 & 39 \\
\hline $11 \mathrm{a} \rightarrow \mathrm{TS} 1$ & 101 & 93 & 106 \\
\hline $11 b \rightarrow 10+H$ & 108 & 83 & 87 \\
\hline $10+\mathrm{H} \rightarrow$ TS2 & 10 & 26 & 32 \\
\hline $11 \mathrm{~b} \rightarrow \mathrm{TS} 2$ & 117 & 109 & 120 \\
\hline $11 c \rightarrow 10+\mathrm{H}$ & 99 & 72 & 76 \\
\hline $10+\mathrm{H} \rightarrow$ TS3 & 9 & 29 & 37 \\
\hline $11 \mathrm{c} \rightarrow \mathrm{TS} 3$ & 108 & 101 & 113 \\
\hline
\end{tabular}

an units of $\mathrm{kJ} \mathrm{mol}^{-1}$ and including zero-point vibrational energies.

${ }^{b}$ From averaged B3LYP and PMP $2 / 6-311++\mathrm{G}(3 \mathrm{df}, 2 \mathrm{p})$ single point energy calculations.

${ }^{c}$ From linear expansion: $E[\operatorname{CCSD}(\mathrm{T}) / 6-311++\mathrm{G}(3 \mathrm{df}, 2 \mathrm{p})] \approx E[\operatorname{CCSD}(\mathrm{T}) / 6-311 \mathrm{G}(\mathrm{d}, \mathrm{p})]+E[\mathrm{PMP} 2 / 6-311++\mathrm{G}(3 \mathrm{df}, 2 \mathrm{p})]-E[\mathrm{PMP} 2 / 6-311 \mathrm{G}(\mathrm{d}, \mathrm{p})]$ 


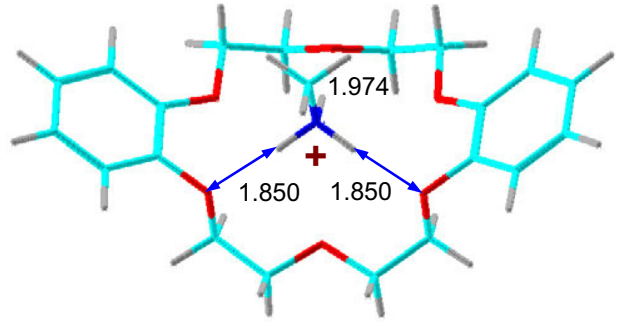

$12^{+}$

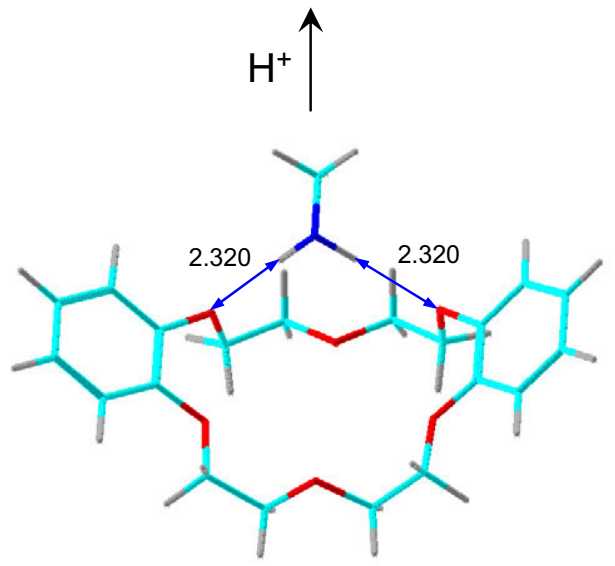

$13 a$

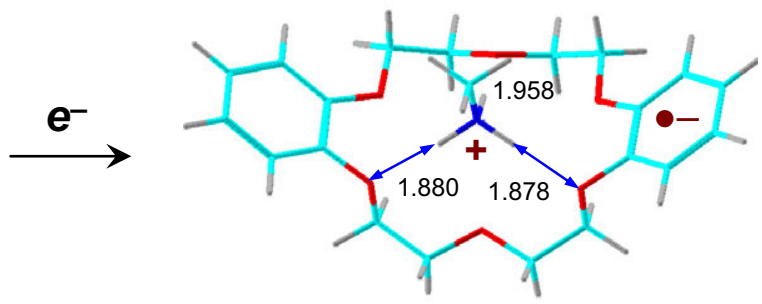

12

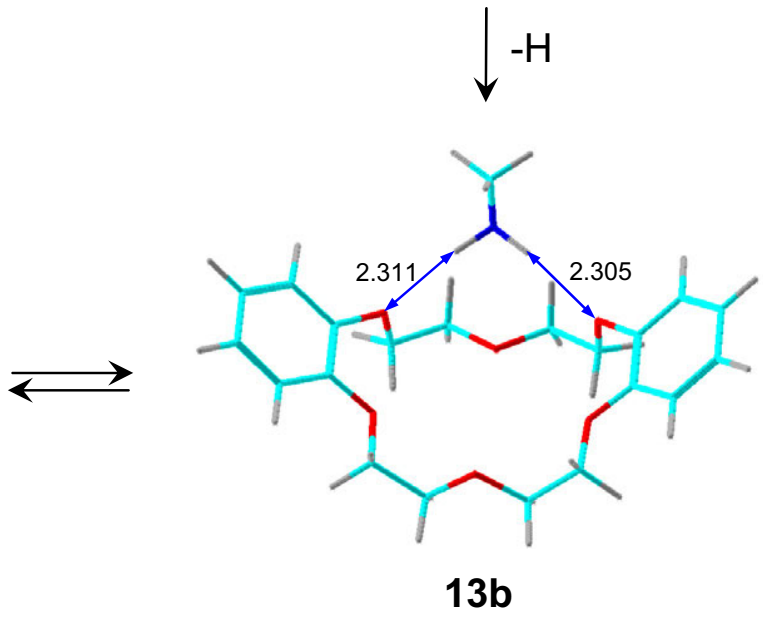

Scheme 5 other remote nonreduced ammonium group rather than from the proximate $\mathrm{NH}_{2}$ group produced by the first $\mathrm{H}$-atom transfer. The specific H-transfer from the ammonium groups, as established by deuterium labeling, excludes a relay-like mechanism for the $\mathbf{Z}$ ion formation in which the $(\mathrm{DBCE}+\mathrm{H})$ radical would transfer a hydrogen atom to the ammonium-coordinated DBCE ligand, which would then receive an ammonium proton upon dissociation forming the $\mathbf{Z}$ fragment ion. If such a mechanism were operative, at least two hydrogen atoms in (DBCE + $\mathrm{H})$, e.g., the original aromatic hydrogen and that transferred to that position from the reduced ammonium would become equivalent for transfer to the other DBCE. Thus, a $\mathbf{Z}$ ion from such a mechanism would contain $\leq 50 \% \mathrm{D}_{2}$ and $\geq 50 \% \mathrm{D}_{1}$ in contrast to experiment $\left(77 \% \mathrm{D}_{2}\right.$ and $23 \% \mathrm{D}_{1}$, vide supra).

The calculated energies indicate an exothermic migration of a hydrogen atom from the reduced ammonium group onto the DBCE ligand. This exothermicity can be estimated to be close to $100 \mathrm{~kJ} \mathrm{~mol}^{-1}$ on the basis of the $\mathrm{N}-\mathrm{H}$ bond dissociation energy in a crownsolvated alkylammonium radical $\left(-28 \mathrm{~kJ} \mathrm{~mol}^{-1}\right)$ [35] and the hydrogen atom affinity of DBCE $\left(73 \mathrm{~kJ} \mathrm{~mol}^{-1}\right.$, Table 1). When a (DBCE $+\mathrm{H})$ ligand is formed by hydrogen transfer, its binding to the alkanediamine $\mathrm{NH}_{2}$ group is presumably very weak, as judged by the low stability of neutral complexes $\mathbf{1 3} \mathbf{a}$ and $\mathbf{1 3} \mathbf{b}$, which require dissociation energies of only 17 and $21 \mathrm{~kJ} \mathrm{~mol}^{-1}$, respectively, to lose the neutral amine. Thus, the charge reduced complex $\left(4-2 \mathrm{DBCE}^{+\cdot}\right)$ is expected to dissociate to $4-1 \mathrm{DBCE}^{+}$, as observed. However, to produce the $\mathbf{Z}$ fragment, the $(\mathrm{DBCE}+\mathrm{H})$ moiety must migrate to the other nonreduced ammonium end, the migration must be kinetically competitive with dissociation, and it must be followed by a proton transfer. However, energy estimates suggest that $(\mathrm{DBCE}+\mathrm{H})^{\circ}$ is unlikely to abstract a proton from a crown-coordinated ammonium group. For example, the proton affinity of the DBCE. $\mathrm{CH}_{3} \mathrm{NH}_{2}$ complex $13 \mathrm{~b}\left(1122 \mathrm{~kJ} \mathrm{~mol}{ }^{-1}\right)$ substantially exceeds the proton affinity of $(\mathrm{DBCE}+\mathrm{H})^{\circ}(941 \mathrm{~kJ}$ $\mathrm{mol}^{-1}$ ), which is comparable to that of DBCE $(939 \mathrm{~kJ}$ $\mathrm{mol}^{-1}$, Table 1).

An alternative pathway was considered in which $(\mathrm{DBCE}+\mathrm{H})$; , formed at the reduced end, first displaced the DBCE ligand at the nonreduced ammonium group, and the intermediate complex then dissociated by proton transfer to (DBCE $+\mathrm{H}$ ) and loss of neutral alkanediamine. Such a mechanism is energetically feasible, because (DBCE $+\mathrm{H})^{\circ}$ and DBCE have similar affinities to ammonium ions (e.g., respectively, 256 and $245 \mathrm{~kJ} \mathrm{~mol}^{-1}$ for methylammonium) and thus the ligand displacement is expected to be nearly thermoneutral or slightly exothermic. We note, however, that the ECD spectra did not show intermediates of the $(n-1 \mathrm{DBCE}+\mathrm{H})^{+\cdot}$ type while $n-1 \mathrm{DBCE}^{+}$were abundant. Possibly $(\boldsymbol{n}-1 \mathrm{DBCE}+\mathrm{H})^{+}$. intermediate complexes were transiently formed but eliminated an $\mathrm{H}$ atom in competition with the elimination of the neutral alkanediamine. These dissociations have comparable endothermicities, e.g., $75 \mathrm{~kJ}$ 


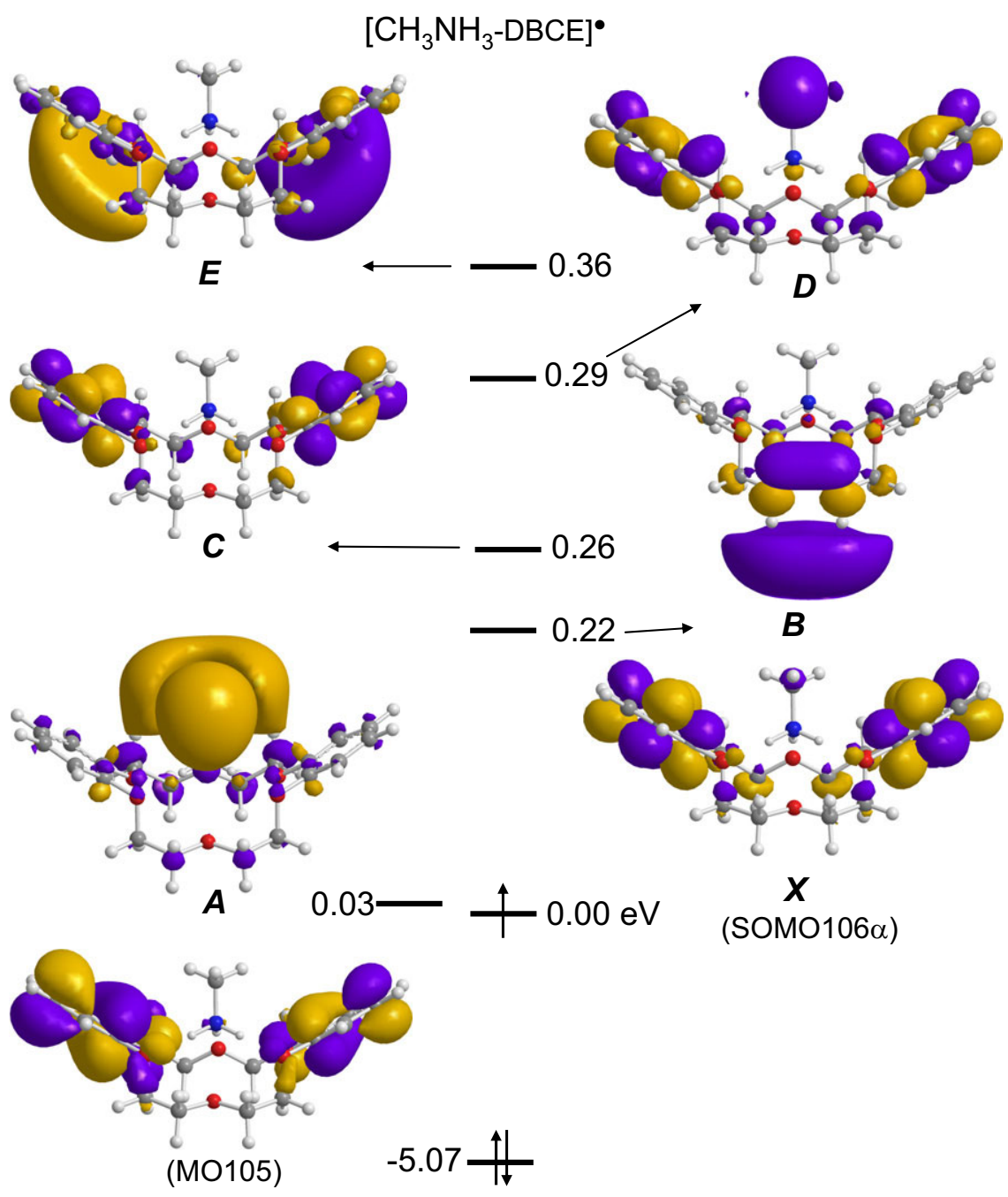

Figure 4. Electronic states in the DBCE. $\mathrm{CH}_{3} \mathrm{NH}_{3}$ complex from TD-B3LYP/6-311++G(2d,p) calculations. Orbital phases are distinguished by purple and gold color. Electronic state energies are given in electron volts. Those for the $A-E$ excited states correspond to vertical single electron excitation from the $X$ state.

$\mathrm{mol}^{-1}$ for loss of $\mathrm{H}$ from $(\mathrm{DBCE}+\mathrm{H})^{\cdot}$ and $62 \mathrm{~kJ} \mathrm{~mol}^{-1}$ for proton transfer from $4^{+}$to $(\mathrm{DBCE}+\mathrm{H})$. An attractive feature of the proposed mechanism is that it is consistent with the observed dependence of the $\mathbf{Z}$ ion relative intensity on the alkanediamine chain length where the longer amines give more abundant $\mathrm{Z}$ ions. 1,4-Butanediamine has the highest proton affinity of the alkanediamines under study [48] and is expected to be least efficiently deprotonated by $(\mathrm{DBCE}+\mathrm{H})^{\cdot}$ upon dissociation of the complex.

The mechanistic details for the DBCE ligand displacement are less clear. The ligand displacement requires a substantial reorientation of the remote $(\mathrm{DBCE}+\mathrm{H})^{\circ}$ and DBCE groups in an ion-molecule complex. Analogous reorientations of remote groups in ion-molecule complexes have been reported by Longevialle to occur in ion dissociations of bifunctional steroids [53-56], and the phenomenon has been analyzed by Morton [57, 58]. We investigated a "bead-on-the-string" mechanism [7] in which the alkanediamine chain slides through the (DBCE $+\mathrm{H})$ ligand and thus brings it close to the opposite ammonium end to displace the DBCE ligand. We used Ar instead of an alkylamine chain because Ar has a similar van der Waals radius (1.88 $\AA$ ) as methylene and amino groups (1.89 and $1.76 \AA$, respectively) [59], and the calculations were aided by symmetry. However, the DBCE cavity appears to be too small to allow for an unobstructed passage of an Ar atom or an alkyl chain. Calculations for model DBCE-Ar complexes indicated a $>50 \mathrm{~kJ} \mathrm{~mol}^{-1}$ energy barrier for passing an Ar atom through the DBCE cavity. In addition, the Ar atom tended to escape through the open end of the DBCE bowl. This indicated that the DBCE ligand would slip off the alkanediamine chain rather than riding it towards the other end. Hence, the "bead-on-the-string" reorganization does not seem to be favorable, and the detailed mechanism of the formation of the $\mathbf{Z}$ ion remains to be yet elucidated. 


\section{Conclusions}

Electron capture by dibenzo-18-crown-6-ether $1, n$ alkanediammonium complexes triggers exothermic hydrogen transfer from the reduced ammonium group to the crown ether aromatic ring. This is followed by ligand reorientation, elimination of one crown molecule, and dissociation of the intermediate ion-molecule complex to yield a protonated crown ether radical or a protonated alkanediamine. This unusual dissociation is caused by the high hydrogen atom affinity of the aromatic rings in the dibenzocrown ether ligand.

\section{Acknowledgments}

The authors gratefully acknowledge support by the National Science Foundation (grants CHE-0750048 for experiments and CHE-0342956) for computations. The Department of Chemistry Computer Facility has been jointly supported by the NSF and University of Washington. The authors thank Jace W. Jones for technical assistance with ECD spectra measurements.

\section{References}

1. Dearden, D. V.; Chu, I.-H. Relative Ammonium Ion Affinities of 18-Crown-6 and the Isomers of Dicyclohexano-18-Crown-6. J. Inclusion Phenom. Mol. Recogn. Chem. 1997, 29, 269-282.

2. Liang, Y.; Bradshaw, J. S.; Dearden, D. V. The Thermodynamic Basis for Enantiodiscrimination: Gas-Phase Measurement of the Enthalpy and Entropy of Chiral Amine Recognition by Dimethyldiketopyridino-18Crown-6. J. Phys. Chem. A 2002, 106, 9665-9671.

3. Wilson, J. J.; Kirkovits, G. J.; Sessler, J. L.; Brodbelt, J. S. Photodissociation of Noncovalent Peptide-Crown Ether Complexes. J. Am. Soc. Mass Spectrom. 2008, 19, 257-260.

4. Kellersberger, K. A.; Anderson, J. D.; Ward, S. M.; Krakowiak, K. E.; Dearden, D. V. Encapsulation of N2, O2, Methanol, or Acetonitrile by Decamethylcucurbit[5]uril(NH4+)2 Complexes in the Gas Phase: Influence of the Guest on "Lid" Tightness. J. Am. Chem. Soc. 2001, 123, 11316-11317.

5. Zhang, H.; Paulsen, E. S.; Walker, K. A.; Krakowiak, K. E.; Dearden D. V. Cucurbit[6]uril Pseudorotaxanes: Distinctive Gas-Phase Dissociation and Reactivity. J. Am. Chem. Soc. 2003, 125, 9284-9285.

6. Osaka, I.; Kondou, M.; Selvapalam, N.; Samal, S.; Kim, K.; Rekharsky, M. V.; Inoue, Y.; Arakawa, R. Characterization of Host-Guest Complexes of Cucurbit[n]uril $(n=6,7)$ by Electrospray Ionization Mass Spectrometry. J. Mass Spectrom. 2006, 41, 202-207.

7. Zhang, H.; Ferrell, T. A.; Asplund, M. C.; Dearden, D. V. Molecular Beads on a Charged Molecular String: $\alpha, \omega$-Alkyldiammonium Complexes of Cucurbit[6]uril in the Gas Phase. Int. J. Mass Spectrom. 2007, $265,187-196$

8. Ling, Y.; Mague, J. T.; Kaifer, A. E. Inclusion Complexation of Diquat and Paraquat by the Hosts Cucurbit[7]uril and Cucurbit[8]uril. Chem. Eur. J. 2007, 13, 7908-7914

9. Stone, M. M.; Franz, A. H.; Lebrilla, C. B. Noncovalent CalixareneAmino Acid Complexes Formed by MALDI-MS. J. Am. Soc. Mass Spectrom. 2002, 13, 964-974.

10. Arai, S.; Ishihara, S.; Takeoka, S.; Ohkawa, H.; Shibue, T.; Nishide, H. Stability of Porphyrin-calix[4]arene Complexes Analyzed by Electrospray Ionization Mass Spectrometry. Rapid Commun. Mass Spectrom. 2004, 18, 2065-2068.

11. Rozhenko, A. B.; Schoeller, W. W.; Letzel, M. C.; Decker, B.; Agena, C.; Mattay, J. Calixarenes as Hosts for Ammonium Cations: A Quantum Chemical Study and Mass Spectrometric Investigations. Chem. Eur. J. 2006, 12, 8995-9000.

12. Da Silva, E.; Rousseau, C. F.; Zanella-Cleon, I.; Becchi, M.; Coleman, A. W. Mass Spectrometric Determination of Association Constants of Bovine Serum Albumin (BSA) with para-Sulfonato-Calix[n]arene Derivatives. I. Inclusion Phenom. Macrocycl. Chem. 2006, 54, 53-59.

13. Kellersberger, K. A.; Dejsupa, C.; Liang, Y.; Pope, R. M.; Dearden, D. V. Gas Phase Studies of Ammonium-Cyclodextrin Compounds Using Fourier Transform Ion Cyclotron Resonance. Int. J. Mass Spectrom. 1999, 193, 181-195.

14. Garcia, B.; Ramirez, J.; Wong, S.; Lebrilla, C. B. Thermal Dissociation of Protonated Cyclodextrin-Amino Acid Complexes in the Gas Phase. Int. J. Mass Spectrom. 2001, 210/211, 215-222.

15. Lebrilla, C. B. The Gas-Phase Chemistry of Cyclodextrin Inclusion Complexes. Acc. Chem. Res. 2001, 34, 653-661.

16. Vrkic, A. K.; O'Hair, R. A. J.; Lebrilla, C. B. Unusual Covalent BondBreaking Reactions of $\beta$-Cyclodextrin Inclusion Complexes of Nucleo-
bases/Nucleosides and Related Guest Molecules. Eur. J. Mass Spectrom. 2003, 9, 563-577.

17. Guo, M.; Song, F.; Liu, Z.; Liu, S. Characterization of Noncovalent Complexes of Rutin with Cyclodextrins by Electrospray Ionization Tandem Mass Spectrometry. J. Mass Spectrom. 2004, 39, 594-599.

18. Wen, X.; Liu, Z.; Zhu, T. Mass Spectrometry and Molecular Modeling Studies on the Inclusion Complexes Between $\alpha-, \beta$-Cyclodextrins and Simvastatin. Chem. Phys. Lett. 2005, 405, 114-117.

19. Ahn, S.; Cong, X.; Lebrilla, C. B.; Gronert, S. Zwitterion Formation in Gas-Phase Cyclodextrin Complexes. J. Am. Soc. Mass Spectrom. 2005, 16, $166-175$.

20. Li, H.; Zhou, J.; Tang, F.; Yuan, G. Investigation of Noncovalent Complexes Between $\beta$-Cyclodextrin and Polyamide Acids Containing N-Methylpyrrole and N-Methylimidazole by Electrospray Ionization Mass Spectrometry. J. Am. Soc. Mass Spectrom. 2006, 17, 9-14.

21. Zhang, H.; Chen, G.; Wang, L.; Ding, L.; Tian, Y.; Jin, W.; Zhang, H. Study on the Inclusion Complexes of Cyclodextrin and Sulphonated azo Dyes by Electrospray Ionization Mass Spectrometry. Int. J. Mass Spectrom. 2006, 252, 1-10.

22. Zhang, M.; Shi, Z.; Bai, Y.; Gao, Y.; Hu, R.; Zhao, F. Using Molecular Recognition of $\beta$-Cyclodextrin to Determine Molecular Weights of Low-Molecular-Weight Explosives by MALDI-TOF Mass Spectrometry. J. Am. Soc. Mass Spectrom. 2006, 17, 189-193.

23. Greisch, J.-F.; Kyritsoglou, S.; Leyh, B.; De Pauw, E. Mass spectrometric study of the ionized C60: $(\gamma$-Cyclodextrin $) 2$ Inclusion Complex by Collision Induced Dissociation. J. Mass Spectrom. 2008, 43, 242-250.

24. Schug, K.; Lindner, W. Development of a Screening Technique for Noncovalent Complex Formation Between Guanidinium- and PhosphonateFunctionalized Amino Acids by Electrospray Ionization Ion Trap Mass Spectrometry: Assessing Ionization and Functional Group Interaction. Int. I. Mass Spectrom. 2004, 235, 213-222.

25. Beyeh, N. K.; Feher, D.; Luostarinen, M.; Schalley, C. A.; Rissanen, K. Synthesis of Chiral Resorcinarene-Based Hosts and a Mass Spectrometric Study of Their Chemistry in Solution and the Gas Phase. J. Inclusion Phenom. Macrocycl. Chem. 2006, 56, 381-394.

26. Liebig, T.; Luening, U.; Grotemeyer, J. Supramolecular Clusters Between Carbohydrates and Concave Pyridines. Detection in the Gas Phase by Resonance-Enhanced Multiphoton Ionization Reflectron Time-of-Flight Mass Spectrometry. Eur. J. Mass Spectrom. 2006, 12 117-120.

27. Makinen, M.; Kalenius, E.; Neitola, R.; Rissanen, K.; Vainiotalo, P. The Complex Formation of Tetracyclohexylammonium C1-Resorcinarene with Various Guests-an Electrospray Ionization Fourier Transform Ion Cyclotron Resonance Mass Spectrometry study. Rapid Commun. Mass Spectrom. 2008, 22, 1377-1383.

28. Di Tullio, A.; Reale, S.; De Angelis, F. Molecular Recognition by Mass Spectrometry. J. Mass Spectrom. 2005, 40, 845-865.

29. Cong, X.; Czerwieniec, G.; McJimpsey, E.; Ahn, S.; Troy, F. A.; Lebrilla, C. B. Structural Relationships in Small Molecule Interactions Governing Gas-Phase Enantioselectivity and Zwitterionic Formation. J. Am. Soc. Mass Spectrom. 2006, 17, 442-452.

30. Weimann, D. P.; Schalley, C. A. Host-Guest Chemistry of Self-Assembling Supramolecular Capsules in the Gas Phase. Supramol. Chem. 2008, 20, 117-128.

31. Sherman, C. L.; Brodbelt, J. S. Partitioning Model for Competitive Host-Guest Complexation in ESI-MS. Anal. Chem. 2005, 77, 2512-2523.

32. Grigorean, G.; Gronert, S.; Lebrilla, C. B. Enantioselective Gas-Phase Ion-Molecule Reactions in a Quadrupole Ion Trap. Int. J. Mass Spectrom. 2002, 219, 79-87.

33. Grigorean, G; Cong, X.; Lebrilla, C. B. Chiral Analyses of Peptides by Ion/Molecule Reactions. Int. J. Mass Spectrom. 2004, 234, 71-77.

34. Chakraborty, T.; Holm, A. I. S.; Hvelplund, P.; Nielsen, S. B.; Poully, J.-C.; Worm, E. S.; Williams, E. R. On the Survival of Peptide Cations After Electron Capture: Role of Internal Hydrogen Bonding and Microsolvation. J. Am. Soc. Mass Spectrom. 2006, 17, 1675-1680.

35. Holm, A. I. S.; Larsen, M. K.; Panja, S.; Hvelplund, P.; Nielsen, S. B. Leib, R. D.; Donald, W. A.; Williams, E. R.; Hao, C.; Tureček, F. Electron capture, femtosecond electron transfer and theory: A study of noncovalent crown ether 1,n-diammonium alkane complexes. Int. J. Mass Spectrom. 2008, 276, 116-126.

36. Zubarev, R. A.; Kelleher, N. L.; McLafferty, F. W. Electron Capture Dissociation of Multiply Charged Protein Cations. A Nonergodic Process. J. Am. Chem. Soc. 1998, 120, 3265-3266.

37. Frisch, M. J.; Trucks, G. W.; Schlegel, H. B.; Scuseria, G. E.; Robb, M. A.; Cheeseman, J. R.; Montgomery, J. A. Jr.; Vreven, T.; Kudin, K. N.; Burant, J. C.; Millam, J. M.; Iyengar, S. S.; Tomasi, J.; Barone, V.; Mennucci, B.; Cossi, M.; Scalmani, G.; Rega, N.; Petersson, G. A.; Nakatsuji, H.; Hada, M.; Ehara, M.; Toyota, K.; Fukuda, R.; Hasegawa, J.; Ishida, M.; Nakajima, T.; Honda, Y.; Kitao, O.; Nakai, H.; Klene, M.; Li, X.; Knox, J. E.; Hratchian, H. P.; Cross, J. B.; Adamo, C.; Jaramillo, J.; Gomperts, R.; Stratmann, R. E.; Yazyev, O.; Austn, A. J.; Cammi, R.; Pomelli, C.; Ochterski, J., W.; Ayala, P. Y.; Morokuma, K.; Voth, G. A.; Salvador, P.; Dannenberg, J. J.; Zakrzewski, V. G.; Dapprich, S.; Daniels, A. D.; Strain, M. C.; Farkas, O.; Malick, D. K.; Rabuck, A. D.; Raghavachari, K.; Foresman, J. B.; Ortiz, J. V.; Cui, Q.; Baboul, A. G.; Clifford, S.; Cioslowski, J.; Stefanov, B. B.; Liu, G.; Liashenko, A.; Piskorz, P.; Komaromi, I.; Martin, R. L.; Fox, D. J.; Keith, T.; Al-Laham, M. A.; Peng, C. Y.; Nanayakkara, A.; Challacombe, M.; Gill, P. M. W.; Johnson, B.; Chen, W.; Wong, M. W.; Gonzalez, C.; Pople, J. A. Gaussian 03, Revision $B$ 05; Gaussian, Inc.: Pittsburgh, PA, 2003. 
38. (a) Becke, A. D. A New Mixing of Hartree-Fock and Local DensityFunctional Theories. J. Chem. Phys. 1993, 98, 1372-1377. (b) Becke, A. D. Density Functional Thermochemistry. III. The Role of Exact Exchange. J. Chem. Phys. 1993, 98, 5648-5652. (c) Stephens, P. J.; Devlin, F. J.; Chabalowski, C. F.; Frisch, M. J. Ab Initio Calculation of Vibrational Absorption and Circular Dichroism Spectra Using Density Functional Force Fields. J. Phys. Chem. 1994, 98, 11623-11627.

39. Rauhut, G.; Pulay, P. Transferable Scaling factors for Density Functional Derived Vibrational Force Fields. J. Phys. Chem. 1995, 99, 3093-3100.

40. [caron]Cížek, J.; Paldus, J.; Šroubková, L. Cluster Expansion Analysis for Delocalized Systems. Int. J. Quantum. Chem. 1969, 3, 149-167.

41. Purvis, G. D. III; Bartlett, R. J. A Full Coupled-Cluster Singles and Doubles model: The Inclusion of Disconnected Triples. J. Chem. Phys. 1982, 76, 1910-1918.

42. Curtiss, L. A.; Raghavachari, K.; Pople. J. A. Gaussian-2 Theory Using Reduced Møller-Plesset Orders. J. Chem. Phys. 1993, 98, 1293-1298.

43. Stratmann, R. E.; Scuseria, G. E.; Frisch, M. J. An Efficient Implementation of Time-Dependent Density Functional Theory for the Calculation of Excitation Energies of Large Molecules. J. Chem. Phys. 1998, 109, 8218-8224.

44. Reed, A. E.; Weinstock, R. B.; Weinhold, F. Natural Population Analysis. I. Chem. Phys. 1985, 83, 735-745.

45. Tureček, F.; Chen, X.; Hao, C. Where Does the Electron Go? Electron Distribution and Reactivity of Peptide Cation-Radicals Formed by Electron Transfer in the Gas Phase. J. Am. Chem. Soc. 2008, 130, 8818-8833.

46. Rogers, R. D.; Kurihara, L. K.; Benning, M. M. F-Element/Crown Ether Complexes. 10. Oxidation of Uranium Tetrachloride to Tetrachlorodioxouranate(2-) in the Presence of Crown Ethers: Structural Characterization of Crown Ether Complexed Ammonium Ions. Inorg. Chem. 1987, 26, 4346-4352.

47. Dapporto, P.; Paoli, P.; Matijasic, I.; Tusek-Bozic, L. Crystal Structures of Complexes of Ammonium and Potassium Hexafluorophosphate with Dibenzo-18-Crown-6. Molecular Mechanics Studies on the Uncomplexed Macrocycle. Inorg. Chim. Acta 1996, 252, 383-389.
48. NIST Standard Reference Database Number 69; March, 2003 Release; http://webbook.nist.gov/chemistry.

49. Chung, T. W.; Tureček, F. Selecting Fixed-Charge Groups for ElectronBased Peptide Dissociations. A Computational Study of Pyridinium Tags. Int. J. Mass Spectrom. 2008, 276, 127-135.

50. Yao, C.; Tureček, F. Hypervalent Ammonium Radicals. Competitive $\mathrm{N}-\mathrm{C}$ and $\mathrm{N}-\mathrm{H}$ Bond Dissociations in Methylammonium and Ethylammonium. Phys. Chem. Chem. Phys. 2005, 7, 912-920.

51. Syrstad, E. A.; Tureček, F. Toward a General Mechanism of ElectronCapture Dissociation. J. Am. Soc. Mass Spectrom. 2005, 16, 208-224.

52. Sobczyk, M.; Anusiewicz, I.; Berdys-Kochanska, J.; Sawicka, A.; Skurski, P.; Simons, J. Coulomb-Assisted Dissociative Electron Attachment: Application to a Model Peptide. J. Phys. Chem. A 2005, 109, 250-258.

53. Longevialle, P.; Botter, R. Electron Impact Mass Spectra of Bifunctional Steroids. The Interaction Between Ionic and Neutral Fragments Derived from the Same Parent Ion. Org. Mass Spectrom. 1983, 18, 1-8.

54. Longevialle, P.; Bouchoux, G.; Hoppilliard, Y. Interaction of Remote Functional Groups (Amide and Amine) in Steroidal Compounds After Electron Ionization. Org. Mass Spectrom. 1990, 25, 527-536.

55. Longevialle, P. Ion-Neutral Complexes in the Unimolecular Reactivity of Organic Cations in the Gas Phase. Mass Spectrom. Rev. 1992, 11, 157-192.

56. Longevialle, P.; Lefevre, O. The Role of Ion-Neutral Reorientation in the Unimolecular Reactivity of Metastable Electron-Ionized Amines. Completing Influences of the Size of the Fragments and the Polarity of the Neutral. Rapid Commun. Mass Spectrom. 1996, 10, 621-626.

57. Morton, T. H. Gas Phase Analogs of Solvolysis Reactions. Tetrahedron 1982, 38, 3195-3243.

58. Morton, T. H. The Reorientation Criterion and Positive Ion-Neutral Complexes. Org. Mass Spectrom. 1992, 27, 353-368.

59. Bondi, A. van der Waals Volumes and Radii. J. Phys. Chem. 1964, 68, $441-451$. 